\title{
Optimization of nutrients requirements for bioremediation of spent-engine oil contaminated soils
}

\author{
Gabriel O. Ogbeh ${ }^{\dagger}$, Titus O. Tsokar ${ }^{1}$, Emmanuel Salifu ${ }^{2}$ \\ ${ }^{1}$ Department of Agricultural and Environmental Engineering, Federal University of Agriculture, P.M.B. 2373 Makurdi, Nigeria \\ ${ }^{2}$ Department of Civil and Environmental Engineering, University of Strathclyde, Glasgow, UK
}

\begin{abstract}
This paper presents a preliminary investigation of the optimum nutrients combination required for bioremediation of spent-engine oil contaminated soil using Box-Behnken-Design. Three levels of cow-manure, poultry-manure and inorganic nitrogen-phosphorus-potassium (NPK) fertilizer were used as independent biostimulants variables; while reduction in total petroleum hydrocarbon (TPH) and total soil porosity (TSP) response as dependent variables were monitored under 6-week incubation. Ex-situ data generated in assessing the degree of biodegradation in the soil were used to develop second-order quadratic regression models for both TPH and TSP. The two models were found to be highly significant and good predictors of the response fate of TPH-removal and TSP-improvement, as indicated by their coefficients of determination: $\mathrm{R}^{2}=$ 0.9982 and $R^{2}=1.000$ at $p \leq 0.05$, respectively. Validation of the models showed that there was no significant difference between the predicted and observed values of TPH-removal and TSP-improvement. Using numerical technique, the optimum values of the biostimulants required to achieve a predicted maximum TPH-removal and TSP-improvement of 67.20 and $53.42 \%$-dry-weight per $\mathrm{kg}$ of the contaminated soil were as follows: cow-manure $-125.0 \mathrm{~g}$, poultry-manure $-100.0 \mathrm{~g}$ and NPK-fertilizer $-10.5 \mathrm{~g}$. The observed values at this optimum point were 66.92 and $52.65 \%$-dry-weight as TPH-removal and TSP-improvement, respectively.
\end{abstract}

Keywords: Bioremediation, Biostimulation, Box-Behnken-Design, Hydrocarbons-degrading microbes, Regression models, Spent-engine oil contaminated soil

\section{Introduction}

Since the invention of the internal combustion (IC) engine, there has been a surge in its applications for the manufacture of automobiles and machinery suitable for transportation and industrial production operations and processes. Such automobiles and machinery function only through the use of fuel (petrol) and lubricants in the IC engines. The functionality of IC engines is however, not without pollution risks that can only be minimized, but not eliminated. This often leads to myriads of environmental problems in the absence of any strategy targeted at minimizing the pollutants from the engines. One of such environmental concerns is the handling procedure of spent-engine oils used in IC engines in sub-Saharan African countries. In Nigeria, for instance, over 76 million litres of spent-engine oils is produced annually by auto and generator mechanic workshops, apart from those spilled accidentally from engine exhaust systems during engine operations
$[1,2]$. These are often carelessly discharged as waste oils unto the environment by auto-mechanics during engine servicing [3, 4]. This practice is exacerbated by lack of effective management strategies because of rudimentary regulation and monitoring at the points of generation [5].

Spent-engine oil is the waste oil generated from lubricating oil introduced into the crankcase of IC engines. Oily Lubricants are used in automobile engines to reduce the effects of internal friction due to moving parts, protect against engine wear, serve as cleaning agent by removing contaminants from the engine as well as serve as anticorrosive and cooling agent [5]. Because of these roles that lubricant oil performs in IC engines, it picks up a number of impurities over its useful life in the engine. The waste oil arises due to the high temperature and mechanical strain it undergoes within the IC engines [6]. The constituents of spent-engine oils are influenced by the working mechanism of IC engines and they vary from metal contaminants such as chromium, lead,
This is an Open Access article distributed under the terms of the Creative Commons Attribution Non-Commercial License (http://creativecommons.org/licenses/by-nc/3.0/) which permits unrestricted non-commercial use, distribution, and reproduction in any medium, provided the original work is properly cited.

Copyright (C) 2019 Korean Society of Environmental Engineers
Received July 12, 2018 Accepted November 10, 2018

${ }^{\dagger}$ Corresponding author

Email: gabriel.ogbeh@uam.edu.ng, ogbehgabriel@gmail.com Tel: +234-8038635582

ORCID: 0000-0001-9282-2092 
zinc, copper, steel; that arise from the wearing down of metallic parts of the engine to other constituents such as barium, sulphur, dirt, burnt carbon, ash, lubricates additives, decomposition by-products and high molecular weight aliphatic and aromatic hydrocarbons such as highly toxic polycyclic aromatic hydrocarbons (PAHs) and polychlorinated biphenyls (PCBs) [6, 7]. Most of the constituents of spent-engine oil eventually exist as stable oxides, hydroxides, carbonates, exchangeable cations that are mostly bound to organic matter in the soil $[8,9]$, and are highly toxic to soil microbes and some crops. Notable adverse effects of soil contamination by spent-engine oil have been reported on annual and perennial crops such as tomato (Lycopersicumesculentum), maize (Zea mays) [9], Arachis hypogea [2], eggplants [10] and Amaranthus [11].

Soil is a major component of the natural ecosystems and its sustainability is of utmost importance to biodiversities and bioactivities in many respects. For instance, a polluted soil cannot support agricultural activities such as crop production. The contamination of agricultural soils by any unwholesome agents such as spent-engine oils, may lead to poor soil conditions that can prevent it from supporting the growth of crops and essential soil microorganisms [9]. The poor soil conditions may manifest as poor soil aeration, poor soil porosity, loss of water-holding capacity of the soil, reduction of soil appropriate nutrients, and immobilization of nutrients and reduced ability of plants and microbes to fix nitrogen [12-16]. Generally, the mapping of contaminated soil and the resulting cleanup strategies often take a lot of time and money because they require vast knowledge and diverse skill sets [16].

Although, recycling of spent-engine oil is one of its viable management options, it is rarely carried out in developing nations, because of the high cost of operations involved in it [17]. Therefore, overland disposal of spent-engine oil often becomes the only available option when the oil is no longer needed. The attendant effects of such practice on soils are of adverse environmental significance. A gallon of spent-engine oil can contaminate and pose immense hazard to one million gallons of water, including fauna and flora [18].

Although, a number of physical and chemical amendment technologies such as solvent addition and chemical oxidation have been developed for removing toxic contaminants of petroleum origin from contaminated soil as well as for enhancing soil aeration [18], however, these technologies are disadvantaged by several limitations such as high cost of operation, not environmentally favourable; as they tend to destroy soil texture and other characteristics, and at best, they can only temporarily neutralize the priority pollutants without actually removing the pollutants from the soil bodies [15]. Therefore, biological clean-up techniques have been advocated for the removal of hydrocarbons from petroleum-based soil contamination in recent times - because it is widely adjudged to be safe, environmentally friendly and relatively cheaper when compared to conventional physicochemical methods [16, 19-20].

The ability of some bacteria and fungi to synthesize new cells by metabolically utilizing hydrocarbons gave rise to bioremediation of soil, water, and sediment that are contaminated by petroleum products. A number of environmental and operational factors are considered to be essential for effective bioremediation process, namely: the types of available microorganisms, available nutrients, $\mathrm{pH}$, temperature, soil moisture content, oxygen, soil properties and concentration of pollutants
[16]. On this basis therefore, several studies on bioremediation processes have been undertaken either as bioaugmentation strategy - which involves inoculating into the contaminated soils, appropriate microbes that possess the ability to biochemically degrade the hydrocarbons to synthesize new cells or by biostimulation strategy - which involves the addition of organic and/or inorganic nutrients to contaminated soil to stimulate the growth of essential heterotrophic contaminant-degrading bacteria and fungi [5, 19-21]. However, the choice of the appropriate bioremediation strategy to use in a particular petroleum-contaminated soil is influenced by the deficient factors in the soil microenvironment [16].

Several studies have been conducted to investigate the impacts of nutrients-induced biostimulation strategy on indigenous soil microorganisms' capacity to biodegrade soils contaminated by petroleum products, including spent-engine oil [5, 22-27]. Bioremediation of used motor oil contaminated soil using elephant and horse dung as stimulants was conducted by [25]. The impact of cow dung on the ability of Eleusine indica to remediate crude oil artificially added to a particular soil was studied by [27]; and [28] also investigated whether cow dung can stimulate the bioremediation of soils obtained from automobile mechanic workshop. The potential of poultry droppings to create conducive environment for bacteria and fungi to thrive, thereby biodegrading hydrocarbons as energy source was studied by [5, 29]. Studies were also conducted to assess the extent of bioremediation of some soils artificially contaminated by spent lubricating oil [26] and crude oil [15], when the soils were amended with lime and inorganic nitrogen-phosphorus-potassium (NPK) fertilizer for up to 56-d and 10-week incubations, respectively.

In general, most of these researchers reported that the extent of bioactivities attained within the contaminated soil is directly connected to the nature and amount of the nutrients added. However, deficient or excessive addition of nutrients to the contaminated soils could be counterproductive to biostimulation objective [25]. Especially, if the added nutrients lack essential micronutrients, are toxic to indigenous soil microorganisms or enhance the degradation of added nutrients, while abandoning the major soil contaminants to persist.

To the best of our knowledge, very few studies have investigated the influence of amending spent-engine oil contaminated soils with nutrients combination of different origin as well as the optimal amount of such nutrients combination on the overall efficiency of the biostimulation strategy. The aim of this study was to use Box-Behnken-Design (BBD) under response surface methodology (RSM) to assess the optimum nutrient combinations required by indigenous microorganisms to biodegrade total petroleum hydrocarbons from a spent-engine oil contaminated soil so as to improve its porosity and establish some regression models to predict the fate of such soils, when subjected to biostimulation strategy using cow-manure, poultry-manure and NPK-fertilizer as the independent biostimulant variables.

\section{Materials and Methods}

\subsection{Application of Response Surface Methodology by BBD}

The application of RSM by BBD requires the process factors (i.e., 
independent variables) to satisfy the assumption that the variables are measurable, continuous, and controllable by the experiments, with negligible errors. The following conditions were therefore carried out: experiments were conducted to adequately and reliably measure the dependent variables (i.e., total petroleum hydrocarbon (TPH) and total soil porosity (TSP)); second-order quadric regression response surface models were developed for the dependent variables; the optimal set of experimental parameters (i.e., independent variables) needed to produce the optimum response values were determined; and the direct and interactive effects of the process parameters (factors) were assessed by 3 dimensional graphical plots.

\subsection{Collection and Preparation of Soil and Manure Samples}

Recently polluted soil samples were randomly collected using auger-boring instrument within the topsoil zone at depths ranging from 10 to $30 \mathrm{~cm}$ at the premises of an auto-mechanic workshop in Makurdi, Nigeria. The soil samples were air-dried, homogenized by manual pulverization and sieved through $2 \mathrm{~mm}$ sieves. The soil samples that passed through the sieve were collected and stored in jute bags at room temperature for $24 \mathrm{~h}$. The inherent physical, chemical and microbial properties of the soil sub-samples were determined in the laboratory. The soil $\mathrm{pH}$ was determined by inserting an electrode of a $\mathrm{pH}$ meter into a soil-water sample prepared in a ratio of 1:1 as described by [3]. The organic carbon content of the soil was determined by using the wet combustion method described by Walkley and Black [30] with a Leco 1000 $\mathrm{CHN}$ analyzer and the Macro-Kjeldahl method was used to determine the total nitrogen content of the soil [31]. The soil moisture content was determined by evaporation on a Whatman filter paper No. 1 in an oven set at $105^{\circ} \mathrm{C}$ for $24 \mathrm{~h}$ [29]. The initial total hydrocarbon-degrading microbial population in the contaminated soil was determined by the pour plate method [32]. This was done by preparing a culture medium from agar mineral salt and $1 \%$ spent-engine oil to isolate the hydrocarbon-degrading microbes from the contaminated soil. About $0.1 \mathrm{~mL}$ aliquot of the medium diluted to a factor of 0.001 was placed on a plate and incubated at $30^{\circ} \mathrm{C}$ for approximately five days. The distinct colonies developed on the plate were counted and expressed in colony forming unit per gram (cfu/g). The TPH removal and TSP improvement in the spent-engine contaminated soil samples were determined before and during the bioremediation treatment.

\subsubsection{Assessment of TPH}

The method described by [33] was used to assess the TPH contents of each soil sample in all the bioreactors. This was done by introducing and mixing $5.0 \mathrm{~g}$ of the soil with $20 \mathrm{~mL}$ of hexane, followed by filtering the resulting mixture on a Whatman filter paper No. 1. Thereafter, the filtrate was allowed to dry at room temperature by evaporation of the hexane solvent within a fume cupboard lased with a gentle stream of nitrogen. This was then followed by spectrophotometric determination of the residual TPH content of the soil samples by reading absorbance with the aid of ultra violet range spectrophotometer (Model: Helios Alpha, Helios Beta, UV 1, Aquamate spectro unicam) at $400 \mathrm{~nm}$ with freshly diluted spent-engine oil in hexane as blank sample. The actual concentration values of TPH in the soil samples were meas- ured from a standard curve of absorbance and then multiplied by a dilution factor. The spectrophotometer was initially calibrated by reading the absorbance of spent-engine oil dissolved in the hexane.

\subsubsection{Assessment of TSP}

The TSP of a volume of soil is a measure of how much pore spaces it contains [34]. The TSP was measured by finding the ratio of pore spaces to the total soil volume, as shown in Eq. (1).

$$
\% \text { Tsp }=(\text { pore space } / \text { total volume }) \times 100
$$

The pore space is equivalent to the volume of deionized water introduced to submerge soil sample up to the level attain by equal volume of $50 \mathrm{~mL}$ deionized water in a graduated measuring cylinder [34]. This was done by introducing $50 \mathrm{~mL}$ deionized water into a transparent cup and marking the water level in the cup. The water was then emptied into another container and the cup refilled with sample of the contaminated soils up to the marked level. The deionized water was carefully reintroduced into the cup until it reaches the top of the soils. The volume of the remaining deionized water was subtracted from the total volume $(50 \mathrm{~mL})[34,35]$. This implied that the volume of water added to submerge the soil sample was equivalent to the pore spaces in the soil.

\subsubsection{Collection and assessment of manure samples}

The required cow and poultry manures were collected from the matured cattle and laying chicken pens, respectively from Oracle Farms Limited in Makurdi, Nigeria, where matured cattle are housed by semi-intensive system and laying chickens are kept in battery-cage system. The raw manures were separately pulverized by manual method and passed through $2 \mathrm{~mm}$ sieves. They were thereafter collected and stored in jute bags at room temperature for $24 \mathrm{~h}$ prior to the treatment operation. In order to determine the carbon to nitrogen ratios and other vital properties of the manures, samples were taken from them and analyzed with particular emphasis on the following parameters: organic carbon, total nitrogen, total phosphorus and total potassium contents of each sample. The organic carbon contents of the manure samples were determined by using the Walkley and Black method [30], while their total nitrogen contents were determined by using the regular Macro-Kjeldahl method [31]. The available phosphorus in each

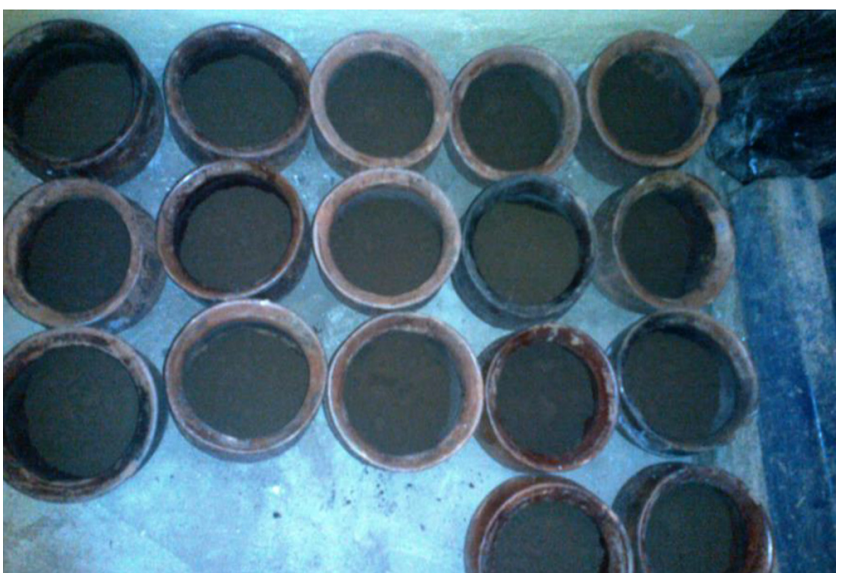

Fig. 1. Bioreactors with spent-engine oil contaminated soil samples. 
manure sample was determined by using the Bray No. 1 method [31] and the potassium content of the samples was determined by flame photometer as described by [3]. The NPK-fertilizer was procured from the New Garage Agro Chemical Shop in Makurdi, Nigeria.

\subsection{Experimental Design and Data Analysis}

Prior to designing the experimental runs, preliminary experiments were carried out to determine the effective ranges of the independent variables (i.e., cow-manure, poultry-manure and NPK-fertilizer) that are suitable for adequate and reliable response of the dependent variables (TPH and TSP). The results of the preliminary experiment indicate that TPH removal and improvement in TSP were most effective in the range of cow-manure from 100.0 to $150.0 \mathrm{~g}$ per $\mathrm{kg}$, poultry-manure in the range of 75.0 to $125.0 \mathrm{~g}$ per $\mathrm{kg}$ and NPK-fertilizer in the range of 2.5 to $8.0 \mathrm{~g}$ per $\mathrm{kg}$ of the spent-engine oil contaminated soil samples.

The statistical software, Design-Expert (version 7.0.0) was used to set up the BBD. The experiments were designed and conducted as follows: 18 earthen pots (bioreactors) were chosen for the experiment as shown in Fig. $1.1 \mathrm{~kg}$ of the air-dried spent-engine oil contaminated soil sample was introduced into each bioreactor and then placed in an undisturbed position at room temperature $\left(30^{\circ} \mathrm{C}\right)$. Treatment

Table 1. Application of Biostimulant Doses to the Contaminated Soil Samples

\begin{tabular}{lccc}
\hline Biostimulant variable & Low level & Medium level & High level \\
\hline Code & $(-1)$ & $(0)$ & $(+1)$ \\
Cow-manure (g) & 100.0 & 125.0 & 150.0 \\
Poultry-manure (g) & 75.0 & 100.0 & 125.0 \\
NPK-fertilizer (g) & 2.5 & 5.0 & 7.5 \\
\hline
\end{tabular}

was administered on the contaminated soil samples in the bioreactors by adding the three independent biostimulants variables according to the coding matrix of BBD shown in Table 1 at three levels (i.e., $-1,0$ and +1) with 17 runs and 1 control. The measured quantity of each independent biostimulant variable was introduced into each designated experimental run (bioreactor) as shown in Table 2. However, the contaminated soil sample used as control was not amended with any biostimulants. The treatment of the soil samples in each bioreactor was monitored for $42 \mathrm{~d}$, while being intermittently stirred twice every week to aerate the samples, thereby enhancing biodegradation of the inherent hydrocarbons in the soil [3].

Treatment response readings in terms of the extent of bioremediation of the spent-engine oil contaminated soil, as indicated by TPH removal and improvement in TSP was progressively monitored at an interval of $14 \mathrm{~d}$, even to the last day of incubation. The attributes of each biostimulants to the hydrocarbons removal and improvement in soil porosity were assessed as coefficients of the independent variables on multiple linear regression models developed at $p \leq 0.05$ significance level.

\subsubsection{Statistical analysis and model development}

Multiple regression analysis was performed on the collected data in order to investigate the nature of the relationship that exists between the factors and the responses. The response variables were fitted to the generalized form of the second-order quadratic regression model in Eq. (2), which can be further expressed as Eq. (3) and (4) containing three linear, three quadratics, and three interactions for each of TPH and TSP, respectively. By using the same Design-Expert (version 7.0.0) software, the significance of the various terms in each of the models was ascertained for TPH removal and TSP improvement of the spent-engine oil con-

Table 2. Coded and Uncoded Box-Behnken Design for Three Independent Variables

\begin{tabular}{|c|c|c|c|c|c|c|}
\hline \multirow{2}{*}{ Run } & \multicolumn{2}{|c|}{ Cow-manure (A) } & \multicolumn{2}{|c|}{ Poultry-manure (B) } & \multicolumn{2}{|c|}{ NPK-fertilizer (C) } \\
\hline & code & Value (g) & code & Value (g) & Code & Value (g) \\
\hline 1 & -1 & 100 & 0 & 100 & -1 & 2.5 \\
\hline 2 & -1 & 100 & -1 & 75 & 0 & 5.0 \\
\hline 3 & 0 & 125 & -1 & 75 & 1 & 7.5 \\
\hline 4 & 0 & 125 & 0 & 100 & 0 & 5.0 \\
\hline 5 & 0 & 125 & 0 & 100 & 0 & 5.0 \\
\hline 6 & -1 & 100 & 0 & 100 & 1 & 7.5 \\
\hline 7 & 1 & 150 & -1 & 75 & 0 & 5.0 \\
\hline 8 & 0 & 125 & 0 & 100 & 0 & 5.0 \\
\hline 9 & 0 & 125 & -1 & 75 & -1 & 2.5 \\
\hline 10 & 1 & 150 & 0 & 100 & 1 & 7.5 \\
\hline 11 & 0 & 125 & 1 & 125 & 1 & 7.5 \\
\hline 12 & 1 & 150 & 1 & 125 & 0 & 5.0 \\
\hline 13 & 1 & 150 & 0 & 100 & -1 & 2.5 \\
\hline 14 & 0 & 125 & 0 & 100 & 0 & 5.0 \\
\hline 15 & 0 & 125 & 0 & 100 & 0 & 5.0 \\
\hline 16 & -1 & 100 & 1 & 125 & 0 & 5.0 \\
\hline 17 & 0 & 125 & 1 & 125 & -1 & 2.5 \\
\hline 18 & control & - & - & - & - & - \\
\hline
\end{tabular}


taminated soil.

$$
\begin{gathered}
\mathrm{Y}=\mathrm{f}(\mathrm{x})=\beta_{0}+\sum_{\mathrm{i}=1}^{\mathrm{k}=3} \beta_{\mathrm{i}} \mathrm{x}_{\mathrm{i}}+ \\
\sum_{\mathrm{i}=1}^{\mathrm{k}=3} \sum_{\mathrm{j}=\mathrm{i}+1}^{\mathrm{k}=3} \mathrm{~B}_{\mathrm{ij}} \mathrm{x}_{\mathrm{i}} \mathrm{x}_{\mathrm{j}}+\sum_{\mathrm{i}=1}^{\mathrm{k}=3} \beta_{\mathrm{ii}} \mathrm{x}_{\mathrm{i}}^{2} \\
\mathrm{Y}_{\mathrm{TPH}}=\mathrm{a}_{0}+\mathrm{a}_{1} \mathrm{~A}+\mathrm{a}_{2} \mathrm{~B}+\mathrm{a}_{3} \mathrm{C}+\mathrm{a}_{11} \mathrm{~A}^{2}+\mathrm{a}_{22} \mathrm{~B}^{2}+ \\
\mathrm{a}_{33} \mathrm{C}^{2}+\mathrm{a}_{12} \mathrm{AB}+\mathrm{a}_{22} \mathrm{AC}+\mathrm{a}_{23} \mathrm{BC} \\
\mathrm{Y}_{\mathrm{TSP}}=\mathrm{a}_{0}+\mathrm{a}_{1} \mathrm{~A}+\mathrm{a}_{2} \mathrm{~B}+\mathrm{a}_{3} \mathrm{C}+\mathrm{a}_{11} \mathrm{~A}^{2}+\mathrm{a}_{22} \mathrm{~B}^{2}+ \\
\mathrm{a}_{33} \mathrm{C}^{2}+\mathrm{a}_{12} \mathrm{AB}+\mathrm{a}_{22} \mathrm{AC}+\mathrm{a}_{23} \mathrm{BC}
\end{gathered}
$$

Where, $a_{0}$ was the value of the fixed response at the center point of the design; $a_{1}, a_{2}$, and $a_{3}$ were the linear coefficients; $\mathrm{a}_{11}, \mathrm{a}_{22}$, and $\mathrm{a}_{33}$ were the quadratic coefficients; $\mathrm{a}_{12}, \mathrm{a}_{13}$, and $\mathrm{a}_{23}$ were the interaction effects coefficients of the regression terms, respectively. $\mathrm{A}, \mathrm{B}$, and $\mathrm{C}$, were the levels of the independent biostimulant variables (i.e., cow-manure, poultry-manure and NPK-fertilizer), respectively. The significance of each coefficient in the models was determined by F-test and $p$-values. F-test indicates whether all the factors and interactions considered in the experimental designs are either statistically significant $(p \leq$ 0.05 ) at $95 \%$ confidence level or not. The regression equations were obtained after analysis of variance, which indicates the level of total petroleum hydrocarbon removed and improvement in the total soil porosity as a function of the three independent biostimulant variables.

\section{Results and Discussion}

\subsection{Properties of the Soil and Manure Samples}

The results of the soil analyses are shown in Table 3. Generally, the results indicate that the presence of the spent-engine oil in the soil had adversely altered the soil microenvironments very significantly. A case in point is the fact that the spent-engine oil contaminated soil did not satisfy the carbon to nitrogen ratio of at least 30 that is required for efficient biochemical processes to take place in the soil [5]. Therefore, natural bioattenuation of the contaminated soil to its original quality would be slow, if not impossible, hence, the need to restore the contaminated soil to its original status through an engineered biostimulation process. There was however, presence of heterotrophic hydrocarbons-degrading microbes in the contaminated soil samples - an average count of $4.3 \times 10^{4} \mathrm{cfu} / \mathrm{g}$ was recorded (see Table 3). This was not surprising in that the presence of hydrocarbons such as PAHs and PCBs in soils have been longed reported to support the growth of microbes in soils [5]. The presence of hydrocarbon-degrading microbes in the contaminated soil might have been enhanced by the prevailing rainy season, during which the soil samples were collected and the fact that spent-engine oil was being disposed in a designated area with little vehicular and human traffic within the workshop premises.

The results of the analyses of the solid cow and poultry manures are also shown in Table 3. The carbons to nitrogen (C:N) ratios of both manures were quite lower than the least recommended value of 30 for an organic fertilizer [5]. However, the C:N ratio value of the cow-manure was considerably higher than that of the poultry-manure. This might be due to the fact that the organic carbon content of the cow-manure was substantially higher than that of the poultry-manure. It is expected however that the combined C:N ratio of the three biostimulant variables will be sufficient

\begin{tabular}{|c|c|c|c|}
\hline Soil parameters & \multicolumn{3}{|c|}{ Values } \\
\hline Textural classification & \multicolumn{3}{|c|}{ Sandy loam } \\
\hline Moisture content & \multicolumn{3}{|c|}{ 46.50-\%-wet weight } \\
\hline Organic carbon $(\mathrm{C})$ & \multicolumn{3}{|c|}{ 35.30-\%-dry weight } \\
\hline Total nitrogen $(\mathrm{N})$ & \multicolumn{3}{|c|}{ 1.82-\%-dry weight } \\
\hline Carbon:nitrogen ratio (C:N) & \multicolumn{3}{|c|}{$18.7: 1$} \\
\hline Total phosphorus (P) & \multicolumn{3}{|c|}{ 1.89-\%-dry weight } \\
\hline Total potassium (K) & \multicolumn{3}{|c|}{ 1.21-\%-dry weight } \\
\hline $\mathrm{pH}$ & \multicolumn{3}{|c|}{6.25} \\
\hline Population of hydrocarbon-degrading microbes(THDO) & \multicolumn{3}{|c|}{$4.3 \times 10^{4} \mathrm{cfu} / \mathrm{g}$} \\
\hline Total petroleum hydrocarbon (TPH) content & \multicolumn{3}{|c|}{$3,548 \mathrm{mg} / \mathrm{kg}$} \\
\hline Total soil porosity (TSP) & \multicolumn{3}{|c|}{$25.7 \%$} \\
\hline Properties of independent biostimulants & A (\%wet wt) & B (\%wet wt) & ${ }^{*} \mathrm{C}(\%)$ \\
\hline Total nitrogen $(\mathrm{N})$ & 3.60 & 3.02 & 3 \\
\hline Total phosphorus (P) & 2.52 & 1.92 & 2 \\
\hline Total potassium (K) & 4.31 & 4.50 & 1 \\
\hline Organic carbon (C) & 45.22 & 36.13 & - \\
\hline Carbon:Nitrogen ratio (C:N) & 12.60 & 11.96 & - \\
\hline
\end{tabular}
to biostimulate the growth of essential heterotrophic contaminant-degrading bacteria and fungi in the contaminated soil being treated. Meanwhile, the values of the other parameters were in close range, except for potassium content of the poultry-manure,

Table 3. Properties of the Spent-Engine Oil Contaminated Soil and the Biostimulants

*As quoted by fertilizer manufacturer 
which was reasonably higher than that of the cow-manure.

In general, the variability recorded in the analytical results of the chemical properties of the cow and poultry manures may have been informed by the fact that these manures originated from different types of animals with different maturity as well as consume different types of feeds. The fact that the animals which produced the manure differ in body size also enables them to have different feeding practices. While cows are monogastric (chew their cud), poultry are not. Hence, solid manure from cow may have different nutrients composition from that generated from poultry. This assertion was accentuated by [36], as they reported that the type of livestock, stage of growth and feeding practices were the primary factors that influence the composition of nutrients from livestock manure. The slightly higher carbon to nitrogen ratio of the cow-manure, as compared to the poultry-manure may be attributed to the high molecular carbon-rich cellulose that characterizes cow feeds.

\subsection{Natural Bioattenuation and Biostimulation Treatment}

\subsubsection{Removal of TPH and improvement in TSP in the control soil samples}

The comparative results of the percentage TPH removal from the contaminated soil and the corresponding improvement in TSP under natural bioattenuation (control) within the 42-d investigation is as shown in Table 4. Apparently, changes were recorded in the properties of the soils contained in all the bioreactors, including the control soil samples. The maximum values recorded for TPH removal and TSP improvement in the control samples right from the first day of incubation to the last (day 42) were 19.20 and $15.10 \%$, respectively for soils contaminated by spent-engine oil in an automobile workshop (see Table 4). As compared to the nutrients-amended samples in the bioreactors, the designed biostimulation strategy of combined nutrients addition to the contaminated soils within the specified incubation periods could be considered to be the most dominant factors responsible for the relatively higher percentage of TPH removal and TSP improvement in the soil samples. Although, the maximum percentage values recorded for TPH removal and TSP improvement for the natural bioattenuation process within the incubation period may yet increase further or decrease, if the experimental period is extended. But, the degree of biodegradation processes in the soil would depend on the available microbes and the nature of the remaining contaminants in the soil [15]. This suggests that the TPH contents of the spent-engine oil contaminated soil may or may not degrade further and the soil porosity may or may not improve further, even without the addition of cow-manure, poultry-manure and NPK-fertilizer.

\subsubsection{Enhanced biodegradation through biostimulants treatment}

The bioremediation experiments were done with high precision and reliability, especially with the relatively higher percentage values of 66.92 and 52.65 recorded as TPH removal and TSP improvement. There were substantial improvements in the properties of the soil samples amended with the three biostimulants combinations in the bioreactors, when compared with the original spent-engine oil contaminated soils shown in Table 3. These im- provements may have been caused by the increased bioactivities within the soils' microenvironment, as a result of the enhanced biostimulation of indigenous microbes due to the addition of the biostimulant variables [25]. The addition of nutrients is needed to increase or enhance the bioactivities of microbes in the soil for effective bioremediation of the contaminated soil to take effects [5]. This further suggests that the addition of the independent biostimulants increased the rate of biodegradation in the soil substantially more than those previous reported in some literatures. For instance, [29] reported that an average of 55.43\% reduction in the total petroleum hydrocarbon was achieved in the crude-oil polluted soil that was amended with poultry droppings; and this was only attained because of increment in heterotrophic bacterial and fungal counts by $4.2 \times 10^{4} \mathrm{cfu} / \mathrm{g}$ and $1.8 \times 10^{4} \mathrm{cfu} / \mathrm{g}$, respectively, but the results obtained from the soil without poultry litters were quite insignificant within $90 \mathrm{~d}$.

The high TPH removal from the spent-engine oil contaminated soil may be attributed to the optimised nutrients added to the soil. According to [24], the augmentation of cow dung on a soil that was artificially contaminated with crude oil helped to enhance the ability of Eleusine indica to reduce the quantity of polycyclic aromatic hydrocarbons and heavy metals from the soil quite significantly. But, excessive addition of the cow dung to the soil encouraged available hydrocarbon-degrading microbes to concentrate on biodegrading the nutrients, while allowing the crude oil to persist in the soil. Also, [5] reported that $38.58 \%$ of TPH contained in the spent-engine oil contaminated soil they studied was removed by natural attenuation, as compared to a maximum value of $84.24 \%$, when $2.5 \mathrm{~kg}$ of the soil was amended with poultry litters up to $30 \%$ of the soil weight within 8 weeks incubation. It was also reported by [26] that lime fertilizer showed remarkable results as a biostimulant for the growth of bacteria and fungi during the bioremediation of spent lubricating oil, however, the extent to which the quantity of the lime fertilizer added to the soil affected the growth of the microbes were neglected. The negligence of the effects of the quantities of the nutrients added to the contaminated soils in most of these studies weakened the reliability of the results - only optimum nutrients required should have been added to the contaminated soils.

When compared to the results reported by [33], the overall results of this study are in reasonable agreement, except for the fact that their investigation was centered on enhanced bioremediation of soil artificially polluted with spent-engine oil. They reported that while only $28.80 \%$ of TPH was removed by natural attenuation process, $66.65 \%$ of TPH was removed from the soils amended with varying combination of NPK-fertilizer, hydrogen peroxide and Tween 80 biostimulants in $42 \mathrm{~d}$ incubation period.

The addition of the independent biostimulants to the spent-engine oil contaminated soils obtained from the automobile workshop increased the rate of biodegradation in the soil substantially. In general, the significance of the increased bioactivities within the contaminated soils during the incubation period was evidenced in the improved TSP, which reflects an overall textural and structural improvement of the soils samples. A textured mineral soil that is in good structural condition for plant growth usually has 
very good pore spaces [37]. This is because the pore spaces are not only important for the storage of water and its movement, but also for the exchange of gases such as oxygen and carbondioxide between the soil and the atmosphere. On the other hand, there was substantial percentage reduction in the TPH contents of the soil samples in all the bioreactors, including the control sample which recorded only $19.20 \%$ TPH removal.

\subsection{Data Interpretation and Statistical Analysis}

\subsubsection{Data interpretation}

The percentage TPH removal and percentage improvement in TSP in run 2 with minimum cow-manure (A), minimum poultry-manure (B) and maximum NPK-fertilizer (C) were the least values recorded, when compared to the other runs. But, as shown in Table 4, a range of high percentage increases in TPH removal and improvement in TSP were recorded in the following runs: 4, 5, 8, 14 and 15 with medium nutrient combinations, as oppose to those recorded in the runs involving both minimum and maximum nutrient combinations. The reasons for this phenomenon are not clear, but may be attributed to the fact that the medium nutrient combinations may have created better conducive microenvironments within each designated bioreactor (run) for the indigenous microorganisms to thrive than those created by the nutrients combined in the other bioreactors (runs 1, 2, 3, 6, 7, 9, 10, 11, 12, 13, 16 and 17).

This observation is at variance to that reported by [33] that the highest set of percentage removal of total petroleum hydrocarbon occurs in runs involving relatively high amount of NPK-fertilizer, Tween 80 and pig manure than otherwise. One of the possible reasons for this might be that the medium values of the set of statistical variables tend to influence the observed values much more than the corresponding individual smaller or larger variables. The other reason may be attributed to the fact that the medium nutrient combinations created better microenvironments in the soils, within each of the bioreactors corresponding to runs 4, 5, 8, 14 and 15 for the inherent microorganisms to thrive, thereby enhancing the biodegradation process that led to the increased percentage TPH removal and TSP improvement. The latter reason may be particularly responsible for what was recorded because the micronutrients (especially carbon and nitrogen) that tend to influence the carbon to nitrogen ratio that determine the degree of biodegradation processes may have been in the required range in these set of bioreactors.

\subsubsection{Statistical analysis and fitting of models}

After conducting the experiments for 17 runs and 1 control of the $\mathrm{BBD}$, the corresponding responses of the dependent variables (TPH and TSP) were statistically analyzed with regards to the coded design matrix in Table 2 . The statistical analyses of the data indicate that the residual values of removable TPH and improvable TSP in the soil, after the incubation period, ranged from 33.08 to $68.30 \%$ and 47.35 to $56.33 \%$, respectively. The seventeen (17) observed experimental responses were used to develop the appropriate models for the dependent response variables. This was made possible because the three independent variables (cow-manure, poultry-manure and NPK-fertilizer) correlate positively with the two response variables under the second-order quadratic regression, as represented by Eq. (2) and (3). Quadratic regression

Table 4. Box-Behnken Design and Experimental and Predicted Results

\begin{tabular}{|c|c|c|c|c|c|c|c|}
\hline \multirow{3}{*}{ Run } & \multicolumn{3}{|c|}{ Experimental design } & \multicolumn{4}{|c|}{ Results } \\
\hline & \multirow{2}{*}{$\begin{array}{c}\text { (A) } \\
\text { code }\end{array}$} & \multirow{2}{*}{$\begin{array}{c}\text { (B) } \\
\text { code }\end{array}$} & \multirow{2}{*}{$\begin{array}{c}\text { (C) } \\
\text { Code }\end{array}$} & \multicolumn{2}{|c|}{$\mathrm{Y}_{1}$, TPH removal (\%) } & \multicolumn{2}{|c|}{$\mathrm{Y}_{2}$, TSP improvement (\%) } \\
\hline & & & & Experiment & Predicted & Experiment & Predicted \\
\hline 1 & -1 & 0 & -1 & 45.38 & 45.61 & 34.40 & 34.41 \\
\hline 2 & -1 & -1 & 0 & 43.92 & 44.22 & 32.01 & 32.02 \\
\hline 3 & 0 & -1 & 1 & 55.25 & 55.21 & 44.80 & 44.81 \\
\hline 4 & 0 & 0 & 0 & 66.89 & 66.56 & 52.63 & 52.63 \\
\hline 5 & 0 & 0 & 0 & 66.05 & 66.56 & 52.61 & 52.63 \\
\hline 6 & -1 & 0 & 1 & 48.94 & 48.68 & 36.30 & 36.27 \\
\hline 7 & 1 & -1 & 0 & 45.25 & 45.52 & 33.00 & 33.00 \\
\hline 8 & 0 & 0 & 0 & 66.78 & 66.56 & 52.64 & 52.63 \\
\hline 9 & 0 & -1 & -1 & 50.8 & 50.26 & 40.30 & 40.27 \\
\hline 10 & 1 & 0 & 1 & 55.04 & 54.81 & 42.60 & 42.59 \\
\hline 11 & 0 & 1 & 1 & 57.78 & 58.31 & 47.10 & 47.13 \\
\hline 12 & 1 & 1 & 0 & 47.84 & 47.54 & 35.40 & 35.38 \\
\hline 13 & 1 & 0 & -1 & 43.68 & 43.94 & 32.75 & 32.77 \\
\hline 14 & 0 & 0 & 0 & 66.92 & 66.56 & 52.60 & 52.63 \\
\hline 15 & 0 & 0 & 0 & 66.15 & 66.56 & 52.65 & 52.63 \\
\hline 16 & -1 & 1 & 0 & 44.65 & 44.38 & 31.70 & 31.69 \\
\hline 17 & 0 & 1 & -1 & 49.29 & 49.33 & 40.01 & 40.00 \\
\hline 18 & control & - & - & 19.20 & - & 15.10 & - \\
\hline
\end{tabular}


statistical models were developed for TPH and TSP from the experimental data, and they are as shown in Eq. (5) and (6):

$$
\begin{gathered}
\mathrm{Y}_{\mathrm{TPH}}=66.53+1.12 \mathrm{~A}+0.54 \mathrm{~B}+3.48 \mathrm{C}+1.95 \mathrm{AC}+ \\
1.01 \mathrm{BC}-13.08 \mathrm{~A}^{2}-8.06 \mathrm{~B}^{2}-5.22 \mathrm{C}^{2} \\
\mathrm{Y}_{\mathrm{TSP}}=52.63+1.17 \mathrm{~A}+0.51 \mathrm{~B}+2.92 \mathrm{C}+0.68 \mathrm{AB}+ \\
1.99 \mathrm{AC}+0.65 \mathrm{BC}-13.07 \mathrm{~A}^{2}-6.53 \mathrm{~B}^{2}-3.04 \mathrm{C}^{2}
\end{gathered}
$$

Where, A is cow-manure concentration; B is poultry-manure concentration; and C is the NPK-fertilizer concentration. The coefficients of a single factor (i.e., the ones in front of $\mathrm{A}, \mathrm{B}$ and C) represent the effects of that particular factor, while the coefficients of two factors (i.e., the ones in front of $A B, A C$ and $\mathrm{BC}$ ), where applicable, and those of second-order terms (i.e., the ones in front of $\mathrm{A}^{2}, \mathrm{~B}^{2}$ and $\mathrm{C}^{2}$ ) represent the interaction between the two factors and quadratic effects, respectively. The terms with positive sign have synergistic effects, while the terms with negative sign have antagonistic effects to the biostimulation process. Only the significant terms, as indicated in the analysis of variance (Table S1), were captured in each model.

As can be seen in each of the models, the residual contributions of the combined nutrients addition to the soil are both positive values, implying that the nutrients exerted synergistic effects on the bioremediation process. Also, while the linear and interactive terms exerted synergistic effects on the removal of TPH and improvement in TSP, the quadratic terms exerted antagonistic effects. However, the linear terms exerted greater positive effects (greater coefficients) than the interactive terms (lesser coefficients). Also, the linear effects exerted by NPK-fertilizer (C) on the removal of TPH and improvement in TSP is greater than those exerted by both cow-manure (A) and poultry-manure (B), the positive interactive influence involving NPK-fertilizer in combination with the other two nutrients (coefficients of $\mathrm{AC}$ and $\mathrm{BC}$ ) is quite greater than the interactive effects exerted by cow-manure and poultry-manure $(\mathrm{AB})$ in the TSP model. The antagonistic effects exerted on the removal of TPH and improvement in TSP through the biostimulation process by the quadratic terms of NPK-fertilizer (coefficient of $\mathrm{C}^{2}$ ) is quite lower than those exerted by both poultry-manure (coefficient of $\mathrm{B}^{2}$ ) and cow-manure (coefficient of $\mathrm{A}^{2}$ ) in that order in each model.

The fitted models for both TPH and TSP were evaluated by considering the validity of the regression equations and the corresponding coefficients of determination $\left(\mathrm{R}^{2}\right)$, as shown in Table $\mathrm{S} 1$. Statistical significance level is defined by probability value that is less than $0.01(p<0.01)$ or $0.05(p<0.05)$ at 99 or $95 \%$ confidence intervals, respectively. The model F-values of 560.49 and $1.46 \times 10^{5}$ imply that the models for TPH and TSP are significant at $p<0.05$ and $95 \%$ confidence intervals, respectively. In each case, there is less than $0.01 \%$ chance that this large model $\mathrm{F}$-value occurs due to noise (i.e., $p<0.0001)$. Hence, all the terms: A, $\mathrm{B}, \mathrm{C}, \mathrm{AB}, \mathrm{AC}, \mathrm{BC}, \mathrm{A}^{2}, \mathrm{~B}^{2}$ and $\mathrm{C}^{2}$ in the quadratic regression models (except the $\mathrm{AB}$ in $\mathrm{TPH}$ model) are significant.

Lack of fit value is designed to indicate whether a particular chosen model adequately describes a set of observed data enough or not. Since, model authenticity increases from linear to quadratic and then to polynomial, a typical lack of fit value can be used to verify whether a chosen model describes the observed data enough or a more complicated model would suffice. In this case, the lack of fit F-values of 2.15 and 3.26 for the TPH and TSP models indicate that the lack of fit is not significant relative to the pure error, respectively. There were 23.67 and $14.20 \%$ chance that large lack of fit F-values for the TPH and TSP models occur due to noise. Because the lack of fit is not significant is good, as the model is required to fit the data. Hence, the quadratic regression models chosen for the data is quite sufficient.

Statistical coefficient of determination $\left(R^{2}\right)$ is a measure of goodness of fit that show the degree of correlation between observed values and predicted values. The $\mathrm{R}^{2}$ values of 0.9986 for TPH and 1.000 for TSP imply that over $99.86 \%$ and $100 \%$ of the variance are attributed to the contributory features of the independent biostimulant variables to the bioremediation processes and that the models are highly significant. For the TPH model, the predicted $\mathrm{R}^{2}$ of 0.9855 suggested reasonable agreement with the adjusted $R^{2}$ of 0.9968 and the predicted $R^{2}$ of 0.999 suggested reasonable agreement with the adjusted $R^{2}$ of 1.000 for the TSP model. Adequate precision measures the signal to noise ratio. A ratio greater than 4 is desirable. The obtained ratios of 57.078 and 938.432 for the TPH and TSP models, respectively, indicate adequate signals and imply that each model can be used to navigate the design space.

The coefficient of variation (CV) being a ratio of standard error estimate to the mean of the observed values can be used to measure model reproducibility. A model with CV less than $10 \%$ is generally considered reproducible. The reasonably low CV values of $9.5 \%$ and $0.69 \%$ obtained for the TPH and TSP models, respectively, indicate that the two experiments were done with high precision and were therefore reliable.

\subsection{Response Surface Plots of Interactive Variables}

Although, the interactive terms exerted synergistic effects on both the removal of TPH and improvement in TSP (as shown in the models), the degree of their influence vary to a reasonable extent. Since, each of the independent variables under study contributed directly or indirectly to TPH removal and improvement in TSP, by influencing the bioactivities of indigenous microorganisms in the soil, it is expected that the interactive effects due to the combination of these variables would exert varying effects on the degree of biostimulation process. By gradually increasing the concentrations of the nutrients combination: cow-manure (A), poultry-manure (B) and NPK-fertilizer (C) from the lower to the higher levels, corresponding increase or decrease in TPH removal and TSP improvement may arise.

In order to evaluate the influence of the significant interactive variables $(\mathrm{AB}, \mathrm{AC}$ and $\mathrm{BC}$ ) on the biostimulation process, the graphical response surface plots shown in Fig. 2, 3 and 4 were developed for the interactive effects between cow-manure and poultry-manure, cow-manure and NPK-fertilizers and poultry-manure and NPK-fertilizers for both the TPH and TSP models, respectively. It can be generally deduced from the Figures that there were varying removal of TPH and improvement in TSP, as the cow-manure increased from $-1(100.0 \mathrm{~g})$ to $+1(150.0 \mathrm{~g})$, poultry-manure increased from $-1(75.0 \mathrm{~g})$ to $+1(125.0 \mathrm{~g})$ and NPK increased from $-1(2.5 \mathrm{~g})$ to 


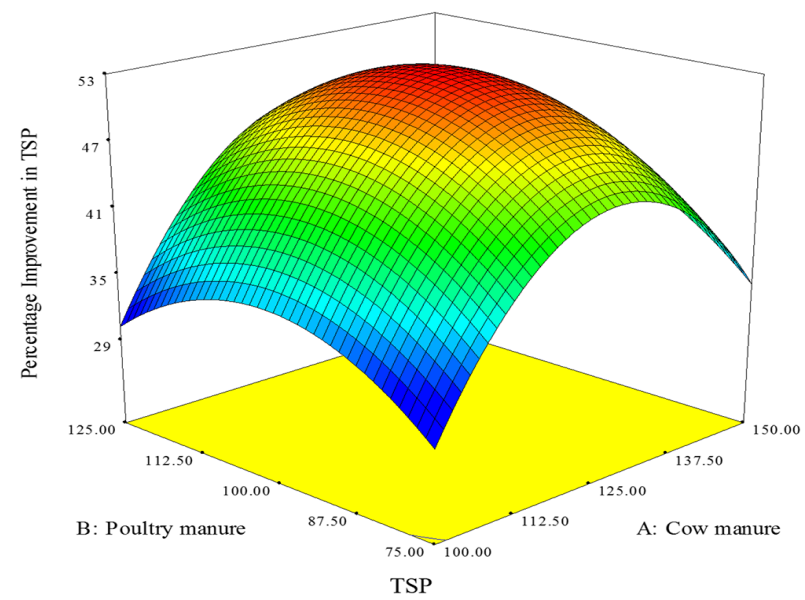

Fig. 2. Surface response plot of the interactive effects between cow manure and poultry manure on biodegradation of the spent-engine oil contaminated soil for improvement in TSP.

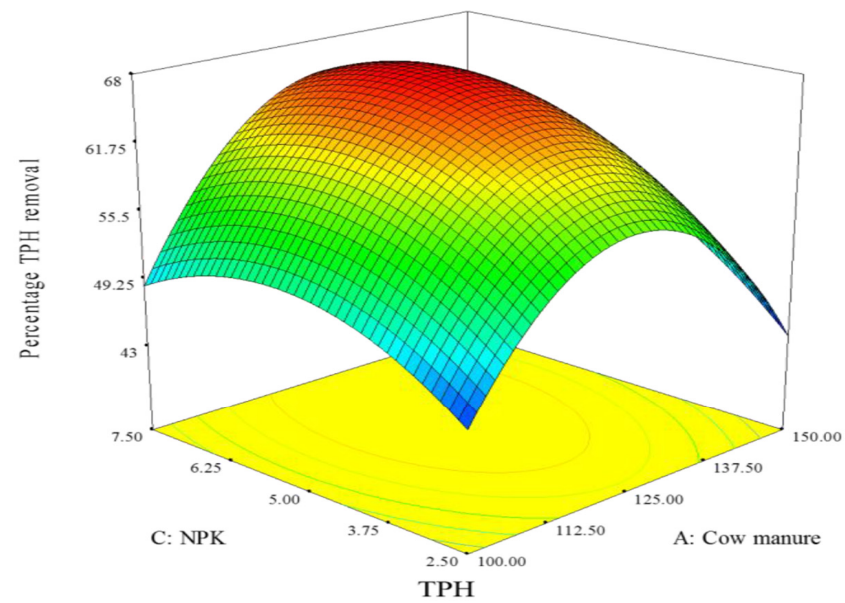

+1 (7.5 g). However, the degree of biodegradation attained under each condition was not comparatively the same. For instance, by keeping the NPK-fertilizer at maximum level and changing the concentration levels of cow-manure and poultry-manure, the interactive effects of the nutrients combinations on the percentage improvement in TSP were positively higher than otherwise as shown in Fig. 2.

\subsection{Nutrients Optimization and Models Validation}

Analyses of the optimum nutrients combination needed by the indigenous microorganisms to degrade maximum TPH content of the contaminated soil and maximum improvement in TSP were done by numerical optimization techniques based on desirability function. This was done by setting the independent variables (nutrients combination) in range that can stimulate biodegradation process and TPH removal and TSP improvement at maximum. The optimum nutrient utilization by biostimulating agents to achieve a predicted maximum TPH removal and TSP improvement of 67.20 (or $2,384.17 \mathrm{mg} / \mathrm{kg}$ ) and $53.42 \%$-dry-weight $/ \mathrm{kg}$ of the contaminated soil samples, respectively were found to be 125.0

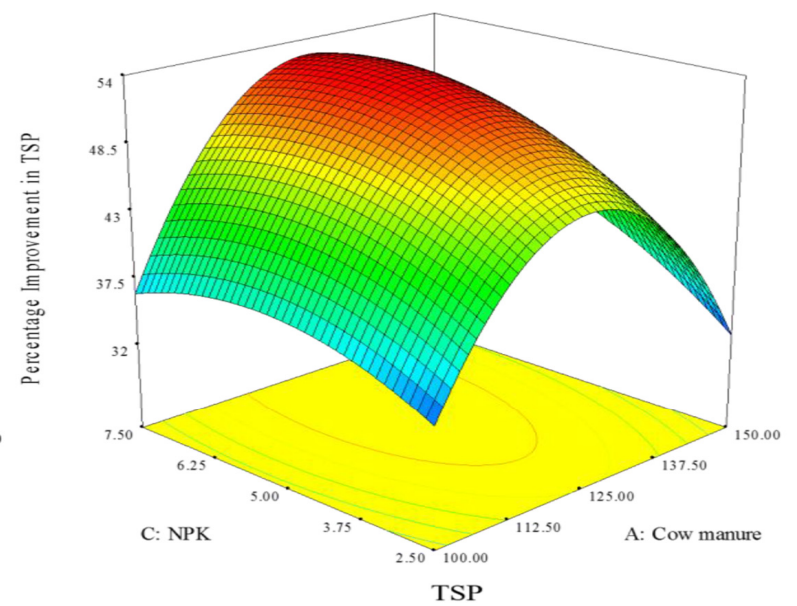

Fig. 3. Surface response plots of the interactive effects between cow manure and NPK-fertilizer on the biodegradation of spent-engine oil contaminated soil for TPH removal and improvement in TSP.
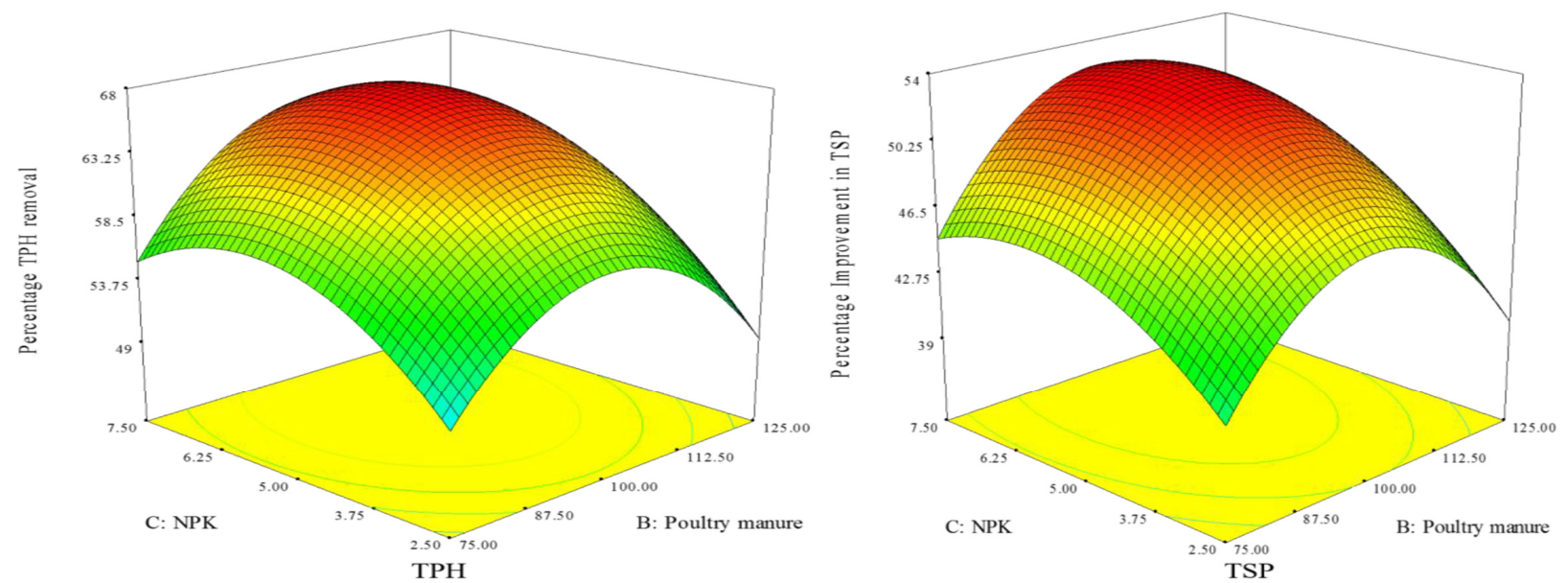

Fig. 4. Surface response plots of the interactive effects between poultry manure and NPK-fertilizer on the biodegradation of spent-engine oil contaminated soil for TPH removal and improvement in TSP. 
g cow-manure, 100.0 g poultry-manure and 10.50 g NPK-fertilizer per kg of spent-engine oil contaminated soils. At this optimum point and desirability of 1.00, the actual observed TPH and TSP percentages were 66.92 (or 2,374.32 mg/kg) and 52.65\%-dryweight $/ \mathrm{kg}$ of the soil, respectively.

Validation of the models at the optimum level of the independent biostimulants was done by determining the standard deviation and percentage error arising from the predicted and actual values of the independent biostimulant variables. The percentage error was determined by using Eq. (7):

Error $=[($ Actual value - predicted value $) /$ Actual value $] \times 100(7)$

For TPH, the error between the predicted and actual values was found to be -1.42 , while that for TSP was found to be -1.46 . There was no obvious significant difference between the predicted and actual values. The response surface plot of the optimization results based on desirability function is as shown in Fig. S1.

The two quadratic regression models for TPH removal and improvement in TSP were significant at $p<0.05$, respectively. The fact that all the terms in the models, except the interactive term $\mathrm{AB}$ in the TPH model are significant suggests that the experiment was done with high accuracy and is reproducible. The interactive term $\mathrm{AB}$ was not significant perhaps because of the fact that the combined inherent nutrient properties of both the cow and poultry manures such as nitrogen, phosphorous and carbon were relatively lower when compared to those involving the NPK-fertilizer. Hence, their relative availabilities for utilization by the soil microbes for enhanced biodegradation of hydrocarbons leading to TPH removal and improvement in TSP is comparatively lower. Subsequently, the exclusion of this non-significant model term $(\mathrm{AB})$ in the TPH model improved its coefficient of determination $\left(\mathrm{R}^{2}\right)$.

\section{Conclusions}

The use of BBD has proven to be a reliable and powerful tool for modelling and optimization of spent-engine oil contaminated soils through biostimulation strategy. Considerable removal of total petroleum hydrocarbon and improvement in total porosity of the soil contaminated by spent-engine oil were achieved through biostimulation with cow-manure, poultry-manure and NPK-fertilizer acting as independent biostimulant variables to the bioremediation process. Maximum total petroleum hydrocarbon reduction of $66.92 \%$-dry-weight from the soil and a corresponding $52.65 \%$-dry-weight improvement in its porosity were observed at the following optimum quantity of nutrients combination: 125.0 g cow-manure, $100.0 \mathrm{~g}$ poultry-manure and $10.5 \mathrm{~g}$ NPK-fertilizer per $\mathrm{kg}$ of the contaminated soils. Reliable predictive quadratic regression models for both dependent responses (TPH and TSP) were found to be highly significant. The results indicate that bioremediation of spent engine oil contaminated soil with the use of cow-manure, poultry-manure and NPK-fertilizer, as biostimulating agents led to gradual and steady reduction of total petroleum hydrocarbon content and improvement in total porosity of the soil within $42 \mathrm{~d}$ incubation period.
In the future, it may be important to compute the combined carbon to nitrogen ratio of these nutrients so as to ensure that the threshold value required for seamless bioremediation process to take place is satisfied. Also, it may be important to characterize the nature of microbes and microbial activity taking place during biostimulation as well as investigate the effects of this treatment strategy on other inorganic contaminants present in the spent-engine oil contaminated soils. As a long-term plan, ecological recovery and restoration and agricultural crop development within soils remedied using these optimal nutrient combinations would be worth investigating.

\section{Acknowledgments}

The authors wish to thank the team of laboratory technologists of the Department of Chemistry, Federal University of Agriculture, Makurdi, Nigeria for their technical support during the assessment of the total petroleum hydrocarbon contents of the soil. The funding of this research and the preparation of the manuscript is from the salary received for services rendered at the Federal University of Agriculture, Makurdi, Nigeria.

\section{References}

1. Faboya OOP. Industrial pollution and waste management. In: Akinjide O, ed. Dimensions of environmental problems in Nigeria. Washington D.C.: Friedrich Ebert Foundation; 1997. p. $12-25$.

2. Osubor CC, Anoliefo GO. Inhibitory effect of spent lubrication oil on the growth and respiratory function of Arachis hypogea L. Benin Sci. Dig. 2003;1:73-79.

3. Ifeanyi UU, Agwu PO. The effect of spent engine oil discharge on soil properties in an automobile mechanic village in Nekede, Imo State, Nigeria. IOSR J. Environ. Sci. Toxicol. Food Technol. 2014;8:28-32.

4. Udonne JD, Onwuma HO. A study of the effects of waste lubricating oil on the physical/chemical properties of soil and the possible remedies. J. Petrol. Gas Eng. 2014;5:9-14.

5. Adams GO, Tawari-Fufeyin P, Ehinomen I. Bioremediation of spent oil contaminated soils using poultry litter. Res. J. Eng. Appl. Sci. 2014;3:118-124.

6. Agency for Toxic Substances and Disease Registry, ATSDR. Toxicology: Profile for used mineral base crankcase oil. Department of Health and Human Services. Public Health Service Press, Atlanta; 1997.

7. Wang J, Jia CR, Wong CK, Wong PK. Characterization of polycyclic aromatic hydrocarbon created in lubricating oils. J. Water Air Soil Pollut. 2000;120:381-396.

8. Umana EJ, Akwaji PI, Markson AA. Bioremediation of spent engine oil contaminated soil by using fungus, Penicillium sp. Int. Lett. Nat. Sci. 2016;59:82-91.

9. Okonokhua BO, Ikhajiagbe B, Anoliefu GO, Emede TO. The effects of spent engine oil on soil properties and growth of maize (Zea mays L.). J. Appl. Sci. Environ. Manage. 2007;11: 147-152. 
10. Anoliefo GO, Edegbai BO. Effect of spent engine oil as a soil contaminant on the growth of two eggplant species Solanum melongena (L) and S. incanum (L). J. Agric. Forest. Fish. 2000;1:21-25.

11. Odjegba VJ, Sadiq AO. Effect of spent engine oil on the growth parameters, chlorophyll and protein levels of Amaranthus hybridus L. Environmentalist 2002;22:23-28.

12. Atuanya EJ. Effect of oil pollution on physical and chemical properties of soil: A case study of waste oil contaminated delta soil in Bendel State, Nigeria. J. Appl. Sci. 1987;55:155-176.

13. Achuba FI, Peretiemo-Clarke BO. Effect of spent engine oil on soil catalase and dehydrogenase activities. Int. Agrophys. 2008;22:1-4.

14. Sathiya-Moorthi P, Deecaraman M, Kalaichelvan PT. Bioremediation of automobile oil effluent by Pseudomonas sp. Adv. Biotechnol. 2008;31:34-37.

15. Chorom M, Sharifi HS, Motamedi H. Bioremediation of a crude oil-polluted soil by application of fertilizers. J. Environ. Health Sci. Eng. 2010;7:319-326.

16. Adams GO, Fufeyin PT, Okoro SE, Ehinomen I. Bioremediation, biostimulation and bioaugmentation: A review. Int. J. Environ. Bioremediat. Biodegrad. 2015;3:28-39.

17. Rashid A, Xiaochun C, Khanji H, Zulifqar AD, Muhammad A. A comparative study of recycling of used engine oil using extraction by composite solvent, single solvent and acid treatment methods. ISRN Chem. Eng. 2013;5:55-67.

18. Filho JLA, Moura LGM, Ramos ACS. Liquid extraction and adsorption on solid surfaces applied to use lubricant oils recovery. Brazilian J. Chem. Eng. 2010;27:687-697.

19. Demnerova K, Mackova M, Spevakova V, et al. Two approaches to biological decontamination of groundwater and soil polluted by aromatics-characterization of microbial population. Int. Microbiol. 2005;8:205-211.

20. Abdulsalam S, Bugaje IM, Adefila SS, Ibrahim S. Comparison of biostimulation and bioaugmentation for remediation of soil contaminated with spent motor oil. Int. J. Environ. Sci. Technol. 2011;8:187-194

21. Pala M, De Carvalho D, Pinto JC, Sant Anna Jr GL. A suitable model to describe bioremediation of a petroleum-contaminated soil. J. Int. Bioremediat. Biodegrad. 2006;58:254-260.

22. Coulon F, Pelletier E, Gourhant L, Delille D. Effects of nutrient and temperature on degradation of petroleum hydrocarbons in contaminated sub-Antarctic soil. Chemosphere 2005;58: 1439-1448.

23. Ayotamuno MJ, Kogbara RB, Ogaj SOT, Probert SD. Bioremediation of a crude-oil polluted agricultural-soil at Port
Harcourt, Nigeria. Appl. Energ. 2006;83:1249-1257.

24. Obinna CN, Yemisi AO. Biostimulation of spent engine oil contaminated soil using Ananas comosus and Solanum tuberosum peels. Environ. Technol. Innov. 2017;8:373-388.

25. Abdulyekeen KA, Muhammad MI, Giwa SO, Absulsalam S. Bioremediation of used motor oil contaminated soil using elephant and horse dung as stimulants. IOSR J. Environ. Sci. Toxicol. Food Technol. 2016;10:73-78.

26. Stephen S, Obaka SL, Ekeyi D. Bioremediation of spent lubricating oil contaminated soil by amendment with lime fertilizer. FUW Trend. Sci. Technol. J. 2016;1:567-569.

27. Essien EB, Ifeanacho MO, Nwachukwu GA. Impact of cow manure augmentation for remediation of crude oil polluted soil by Eleusine indica. J. Appl. Sci. Environ. Manage. 2015;19: 103-107.

28. Adams GO, Tawari-Fufeyin P, Ehinomen I. Laboratory scale bioremediation of soils from automobile mechanic workshops using cow dung. J. Appl. Environ. Microbiol. 2014;2:128-134

29. Okafor UC, Orji MU, Agu KC, et al. Bioremediation of crude oil-polluted soil using broiler-chicken droppings. J. Appl. Environ. Microbiol. 2016;4:75-84.

30. Walkley A, Black CA. Method of soil analysis II. American Society of Agronomy, Madison; 1965. p. 573-590.

31. American Public Health Association, APHA. Standard methods for the examination of water and waste water. 20th ed Washington: American Public Health Association; 1998, p. 1134.

32. Colores GM, Macur RE, Ward DM, Inskeep WP. Molecular analysis of surfactant-driven microbial population shifts in hydrocarbon-contaminated soil. Appl. Environ. Microbiol. 2000;66:2059-2964.

33. Agarry SE, Ogunleye OO. Box-Behnken design application to study enhanced bioremediation of soil artificially contaminated with spent engine oil using biostimulation strategy. Int. J. Energ. Environ. Eng. 2012;3:31.

34. University of Colorado. Measuring porosity and permeability. Environmental Engineering Lesson 3 Worksheet.

35. Grossman RB, Reinsch TG. Bulk density and extensibility: Core method. In: Dane JH, Topp GC, eds. Methods of soil analysis, Part 4, Physical methods. Madison, WI: SSSA, Inc.; 2002. p. 208-228.

36. Manitoba Agriculture, Food and Rural Development, MAFRD. Properties of manure, 2015:agrienv@gov.mb.ca.

37. Ikhajiagbe B, Anoliefo GO. Natural attenuation of a 14-month-old waste engine oil polluted soil. J. Soil Sci. Environ. Manage. 2011;2:184-192. 